\title{
Investigation of NLO Properties of Substituted $(M)$-Tetrathia-[7]-Helicenes by Semiempirical and DFT Methods
}

\author{
CLAUDE A. DAUL, ${ }^{1}$ ILARIA CIOFINI, ${ }^{2}$ VALERY WEBER $^{1}$ \\ ${ }^{1}$ Department of Chemistry, University of Fribourg, CH-1700 Fribourg, Switzerland \\ ${ }^{2}$ Institut fur Anorganische Chemie Universitaet Wuerzburg, D-97074 Wuerzburg, Germany
}

Received 15 October 2001; accepted 30 May 2002

DOI 10.1002/qua.10444

\begin{abstract}
In this article, we propose a theoretical study of static and dynamic polarizability $\alpha$, first hyperpolarizability $\beta$, and second hyperpolarizability $\gamma$ of substituted $(M)$-tetrathia-[7]-helicenes. Both a semiempirical approach, in the case of static and dynamic properties, and density functional theory, in the case of static electric properties, were used. The nonlinear optical (NLO) properties of a set of 10 molecules were investigated to predict the couple of donor-acceptor substituents that could best enhance the optical properties of $(M)$-tetrathia-[7]-helicene.
\end{abstract}

Key words: helicene; nonlinear optics; polarizability; semiempirical methods; $a b$ initio methods

\section{Introduction}

The advent of intense monochromatic light sources in the form of lasers has given great impetus to the field of nonlinear optics (NLO). A number of research groups have been active in the field of NLO materials based on organic molecules and several highly active materials have already been identified [1]. A typical class of such materials consists of molecular aromatic $\pi$ systems in which massive nonlinearities may be achieved with ap-

Correspondence to: V. Weber; e-mail: valery.weber@unifr.ch propriate donor (D) and acceptor (A) substitution on the aromatic part of the molecule.

A typical example is $p$-nitroaniline, which exhibits frequency summing ability comparable to inorganic compounds.

It is well established that the extension of the conjugation path between the electron-donating and -withdrawing groups strongly increases the molecular hyperpolarizability [2-5]. However, the extension of the conjugation path also induces a bathochromic shift of the intramolecular charge transfer absorption band and, thus, the requirement of high transparency to visible light is not met.

Therefore, calculations of the molecular (hyper)polarizabilities and comparisons with correspond- 


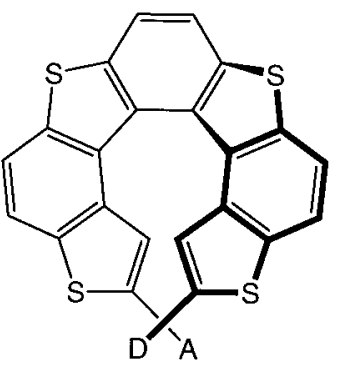

\begin{tabular}{ccc}
$\mathrm{A}$ & $\mathrm{D}$ & num. \\
\hline $\mathrm{H}$ & $\mathrm{H}$ & $\mathbf{1}$ \\
$\mathrm{H}$ & $\mathrm{NH}_{2}$ & $\mathbf{2}$ \\
$\mathrm{NO}_{2}$ & $\mathrm{H}$ & $\mathbf{3}$ \\
$\mathrm{NO}_{2}$ & $\mathrm{NH}_{2}$ & $\mathbf{4}$ \\
$\mathrm{NO}_{2}$ & $\mathrm{OH}$ & $\mathbf{5}$ \\
$\mathrm{CO}_{2} \mathrm{H}$ & $\mathrm{H}$ & $\mathbf{6}$ \\
$\mathrm{NO}_{2}$ & $\mathrm{Cl}$ & $\mathbf{7}$ \\
$\mathrm{CHO}$ & $\mathrm{OH}$ & $\mathbf{8}$ \\
$\mathrm{CHO}$ & $\mathrm{H}$ & $\mathbf{9}$ \\
$\mathrm{CF}$ & $\mathrm{NH}_{2}$ & $\mathbf{1 0}$
\end{tabular}

FIGURE 1. Schematic structure and labeling of substituted $(M)$-tetrathia-[7]-helicenes.

ing experimental data are of importance in establishing the structure-property relationship and estimating the amount of such effects on molecular optical nonlinearity. The synthesis of $(M)$-tetrathia[7]-helicenes (Fig. 1) is demanding [6], and therefore it is appealing to determine a priori by computational methods the pair of substituents (donor, $\mathrm{D}$, and acceptor, A) on the terminal positions of (M)-tetrathia-[7]-helicene that will yield the best nonlinear properties. Experimentally, the optical properties of $(M)$-tetrathia-[7]-helicene helicene have been investigated by Groen et al. [7] (UV-VIS spectra) and Yamada et al. [8] (CD spectra).

Here, we present a theoretical investigation of the NLO properties of $(M)$-tetrathia-[7]-helicene and its substituted derivatives by the means of density functional theory (DFT) and semiempirical methods.

The semiempirical INDO/S (intermediate neglect of differential overlap approximation) methods have been widely use by Abe et al. $[1,9,10]$ to compute first-order hyperpolarizabilities based on the sum-over-states (SOS) method (in particular second harmonic generation) of acceptor-donor molecules, for example, 4-nitroaniline, 4-(dimethylamino)-4'-nitrostilbene, and heterocyclic pyridinium betain. They have shown good agreement between their own experimental values and their semiempirical results as well as with the values obtained from the ab initio molecular orbital (MO) method through the CPHF (coupled-perturbed Hartree-Fock) formalism. Moreover, Hupp et al [11] reported ZINDO-based SOS calculations of the first hyperpolarizability of some porphyrin-based push-pull chromophores and underline the good agreement with the experimental finding [12].

This article is organized as follows: (1) A brief definition of the computed quantities and technical details is followed by (2) the results obtained for the static and dynamic polarizabilities $\alpha_{i j}$, first hyper- polarizabilities $\beta_{i j k}$, and second hyperpolarizabilities $\gamma_{i j k l}$ of substituted (M)-tetrathia-[7]-helicene.

\section{Methods}

\section{NLO PROPERTIES}

The interaction of a molecule with an external electric field of component $E_{i}$ is typically expressed using the following Taylor series expansion of the induced dipole moment [13, 14]:

$$
\mu_{i}=\mu_{i}^{0}+\alpha_{i j} E_{j}+\frac{1}{2 !} \beta_{i j k} E_{j} E_{k}+\frac{1}{3 !} \gamma_{i j k l} E_{j} E_{k} E_{l}+\ldots
$$

where the Einstein summation convention on repeated indices is used, with $i, j, k, l=x, y, z ; \mu_{i}$ is the $i$ th component of the induced dipole moment, $\mu_{i}^{0}$ is the permanent dipole moment, and $\alpha_{i j}, \beta_{i j k}$, and $\gamma_{i j k l}$ are the components of the linear, quadratic, and cubic polarizability tensors, respectively.

The orientationally averaged value of the polarizability, $\bar{\alpha}$, is defined by

$$
\bar{\alpha}=\frac{1}{3} \sum_{i} \alpha_{i i} .
$$

The intrinsic hyperpolarizability $\bar{\beta}$ is given by the magnitude of the vector component of the first hyperpolarizability $\left(\beta_{i j k}\right)$

$$
\bar{\beta}=\left[\sum_{i} \beta_{i}^{2}\right]^{1 / 2},
$$

where $\beta_{i}$ are

$$
\beta_{i}=\frac{1}{3} \sum_{k}\left(\beta_{i k k}+\beta_{k i k}+\beta_{k k i}\right)
$$

and the average value for the second hyperpolarizability, $\bar{\gamma}$, is

$$
\bar{\gamma}=\frac{1}{5}\left[\sum_{i} \gamma_{i i i i}+\frac{1}{3} \sum_{j \neq i}\left(\gamma_{i i j j}+\gamma_{i j i j}+\gamma_{i j j i}\right)\right] .
$$




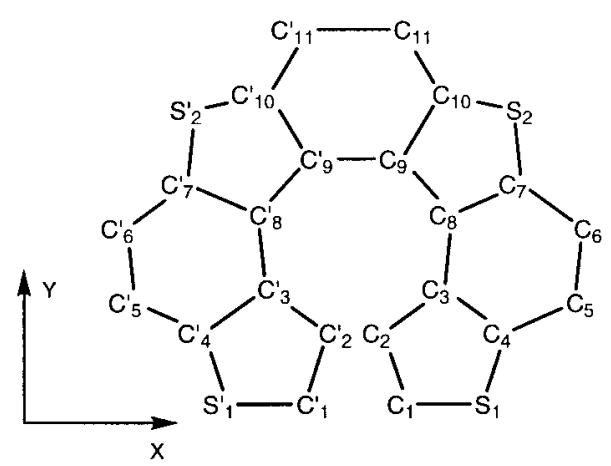

FIGURE 2. Atomic labels of $(M)$-tetrathia-[7]-helicenes.

\section{TECHNICAL DETAILS}

The structure of $(M)$-tetrathia-[7]-helicene and its derivatives is shown in Figure 1 while the labeling scheme used throughout the article is shown in Figure 2. All DFT calculations were carried out using the Gaussian 98 program package [15]. The hybrid Becke-three parameters [16], (B3LYP) exchange correlation functional was applied. Two different split valence basis sets $\left(6-31 G^{* *}\right.$ [17] and 6-311G [18]) were used throughout. Geometry optimizations were performed at the B3LYP/6-311G level. In the case of $(M)$-tetrathia-[7]-helicene, additional geometry optimization at AM1 and B3LYP/ 6-31G** levels were done for comparison. The static polarizabilities ( $\alpha$ and $\beta$ ) were computed at an $a b$ initio DFT level of theory using the coupled-perturbed Kohn-Sham formalism [19, 20] as implemented in the Gaussian 98 program package [21]. In this method, $\alpha$ and $\beta$ are determined from the analytic derivatives of the total energy with respect to the applied electric field. The static and dynamic polarizabilities $(\alpha, \beta$, and $\gamma)$ were also calculated at a semiempirical level using the Fujitsu MOS-F V3L1 program package [22]. In this case, as a first step the wave functions for the ground and excited states are generated by solving the SCF equations of the approximate CNDO/S Hamiltonian according to the parameterization of Del Bene and Jaffe [23] including configuration interaction. Next, the optical tensors are obtained from an SOS [24] procedure within the framework of time-dependent perturbation theory. The SOS was performed with all electronic states generated by singly exciting all electrons from the 40 highest occupied MOs to the 40 lowest unoccupied MOs with respect to the ground state.

For the sake of comparison, the molecular structures used for the calculations of NLO properties both at a semiempirical and DFT level are the optimized B3LYP/6-311G if not otherwise specified.

The following set of electron-withdrawing (acceptors, A) and electron-donating (donors, D) substituents have been selected to test the push-pull effect on NLO properties of (M)-tetrathia-[7]-helicene:

$\mathrm{NO}_{2}, \mathrm{CHO}, \mathrm{COOH}$, and $\mathrm{CF}_{3}$ (acceptors)

$\mathrm{NH}_{2}, \mathrm{OH}$, and $\mathrm{Cl}$ (donors).

The labeling for the nine resulting substituted compounds is reported in Figure 1.

\section{Results and Discussion}

\section{STRUCTURAL ANALYSIS}

In Table I, the optimized geometries of $(M)$ tetrathia-[7]-helicene (1) at the B3LYP/6-311G, B3LYP / 6-31G**, and AM1 levels [25] are compared with the available $X$-ray structure [26]. The geometric parameters are in good agreement with the $\mathrm{X}$ ray diffraction data and only small deviations can be observed, the semiempirical AM1 optimized structure being the closest to the X-ray one. If we analyze two geometric parameters that give an idea of the helicity of the molecule, for example, $r$, the $C_{1}-C_{1}^{\prime}$ distance, and $\varphi$, the $C_{10}-C_{11}-C_{10}^{\prime}-C_{11}^{\prime}$ dihedral angle, note that while the AM1 approach underestimated the $\varphi$ angle both the B3LYP/6-311G and B3LYP $/ 6-31 G^{* *}$ correctly reproduced the screw angle. On the other hand, due to an overestimation of the $\mathrm{H}-\mathrm{H}$ repulsion, these latter methods overestimate the $r$ value by up to $0.3 \AA$.

In the case of substituted helicene, no direct comparison with experiment is possible because most of the molecules are not yet synthesized. In Table II, we report the distances $r$ and the dihedral angles $\varphi$ for substituted helicene. We can see that replacing one or two terminal hydrogen atoms of $\mathbf{1}$ by other substituents does not affect strongly either the distances $r$ or dihedral angles $\varphi$. For example, the maximal deviation on $r$ is $0.284 \AA$ for 2 and the maximal deviation on dihedral angles $\varphi$ is $0.418^{\circ}$ for 9. Therefore, even if such a geometric distortion can play a role in the tuning of the NLO properties, we expect that most of the variations observed with respect to the unsubstituted helicene have to be ascribed to electronic effects of the A-D groups more than to structural ones. 
TABLE I

Bond lengths of 1 optimized at different levels of theory (all values in $\AA$ ).

\begin{tabular}{lrrrrrrr}
\hline & Exp. & AM1 & \multicolumn{1}{c}{$\Delta^{\mathrm{a}}$} & B3LYP/6-311G & \multicolumn{1}{c}{$\Delta^{\mathrm{b}}$} & B3LYP/6-31G ${ }^{* *}$ & \multicolumn{1}{c}{$\Delta^{\mathrm{c}}$} \\
\hline C1-C2 & 1.335 & 1.360 & 0.025 & 1.353 & 0.018 & 1.359 & 0.024 \\
C1—C'1 & 4.043 & 4.133 & 0.090 & 4.346 & 0.303 & 4.317 & 0.274 \\
C1-S1 & 1.711 & 1.684 & -0.027 & 1.811 & 0.100 & 1.744 & 0.033 \\
C2-C3 & 1.431 & 1.450 & 0.019 & 1.447 & 0.016 & 1.440 & 0.009 \\
C2-C'2 & 2.963 & 2.991 & 0.028 & 3.198 & 0.235 & 3.155 & 0.192 \\
C3-C4 & 1.419 & 1.424 & 0.005 & 1.415 & -0.004 & 1.417 & -0.002 \\
C3-C8 & 1.420 & 1.401 & -0.019 & 1.427 & 0.007 & 1.428 & 0.008 \\
C4-C5 & 1.390 & 1.395 & 0.005 & 1.397 & 0.007 & 1.403 & 0.013 \\
C4-S1 & 1.737 & 1.686 & -0.051 & 1.820 & 0.083 & 1.755 & 0.018 \\
C5-C6 & 1.356 & 1.389 & 0.033 & 1.389 & 0.033 & 1.384 & 0.028 \\
C6-C7 & 1.403 & 1.396 & -0.007 & 1.398 & -0.005 & 1.404 & 0.001 \\
C7-C8 & 1.397 & 1.421 & 0.024 & 1.413 & 0.016 & 1.414 & 0.017 \\
C7-S2 & 1.736 & 1.687 & -0.049 & 1.821 & 0.085 & 1.758 & 0.022 \\
C8-C9 & 1.463 & 1.457 & -0.006 & 1.467 & 0.004 & 1.462 & -0.001 \\
C9-C10 & 1.414 & 1.427 & 0.013 & 1.416 & 0.002 & 1.417 & 0.003 \\
C9-C'9 & 1.435 & 1.401 & -0.034 & 1.432 & -0.003 & 1.431 & -0.004 \\
C10-C11 & 1.378 & 1.392 & 0.014 & 1.394 & 0.016 & 1.400 & 0.022 \\
C10-S2 & 1.737 & 1.689 & -0.048 & 1.823 & 0.086 & 1.760 & 0.023 \\
C11-C'11 & 1.351 & 1.392 & 0.041 & 1.391 & 0.040 & 1.385 & 0.034 \\
Num. basis & & & & 400 & & 456 & \\
functions & & & & & & & \\
\hline
\end{tabular}

The numbering scheme is reported in Figure 2.

a Difference between optimized AM1 and X-ray bond lengths.

b Difference between optimized B3LYP/6-311G and X-ray bond lengths.

c Difference between optimized B3LYP/6-31G** and X-ray bond lengths.

\section{NLO RESULTS}

The computed NLO properties of the set of 10 molecules depicted in Figure 1 are reported in Table III. In general, the static properties computed at the semiempirical and $a b$ initio levels are comparable.

At the DFT level, the addition of polarization functions in the $6-31 \mathrm{G}^{* *}$ basis set decreased the computed permanent dipole moment of $\mathbf{1}$ and thus a lower value for $\bar{\beta}$ was obtained.

At the semiempirical level, a strong effect of nuclear geometry on the computed first hyperpolarizability ( $\bar{\beta}$ and $\left.\beta^{\mathrm{SHG}}\right)$ is found. In fact, $\bar{\beta}$ and $\beta^{\text {SHG }}$ computed on the B3LYP/6-311G- and B3LYP/6-31G**-optimized structures strongly differ from the ones obtained using the $\mathrm{X}$-ray structure.

As expected, the push-pull effect improves considerably the optical properties; this fact is well observed in both semiempirical and ab initio methods.

In fact, the average hyperpolarizability $(\bar{\beta})$ computed at the B3LYP/6-311G level increases from
TABLE II

Computed $r$ (in Å) and $\varphi$ (in degrees) for the compounds of $(M)$-tetrathia-[7]-helicenes in Figure 1.

\begin{tabular}{rcc}
\hline & $r$ & $\varphi$ \\
\hline $\mathbf{1}^{\mathrm{a}}$ & 4.043 & -7.245 \\
$\mathbf{1}^{\mathrm{b}}$ & 4.346 & -7.640 \\
$\mathbf{1}^{\mathrm{c}}$ & 4.133 & -6.325 \\
$\mathbf{1}^{\mathrm{d}}$ & 4.317 & -7.488 \\
$\mathbf{2}^{\mathrm{b}}$ & 4.327 & -7.595 \\
$\mathbf{3}^{\mathrm{b}}$ & 4.278 & -7.525 \\
$\mathbf{4}^{\mathrm{b}}$ & 4.262 & -7.475 \\
$\mathbf{5}^{\mathrm{b}}$ & 4.260 & -7.498 \\
$\mathbf{6}^{\mathrm{b}}$ & 4.308 & -7.597 \\
$\mathbf{7}^{\mathrm{b}}$ & 4.289 & -7.572 \\
$\mathbf{8}^{\mathrm{b}}$ & 4.323 & -7.637 \\
$\mathbf{9}^{\mathrm{b}}$ & 4.320 & -7.663 \\
$\mathbf{1 0}^{\mathrm{b}}$ & 4.279 & -7.514 \\
\hline
\end{tabular}

a X-ray structure.

b Optimized B3LYP/6-311G.

c Optimized AM1.

d Optimized B3LYP/6-31G**. 
TABLE III

$A b$ initio (DFT/B3LYP) and CNDO/S computed dipole moments $(\mu)$ and (hyper)polarizability $(\alpha, \beta, \gamma)$ for 1-10.

\begin{tabular}{|c|c|c|c|c|c|c|c|c|c|}
\hline \multirow[b]{2}{*}{ Molecule } & \multicolumn{3}{|c|}{$A b$ initio method } & \multicolumn{6}{|c|}{ Semiempirical method } \\
\hline & $\mu$ & $\bar{\alpha}$ & $\bar{\beta}$ & $\mu$ & $\bar{\alpha}$ & $\bar{\beta}$ & $\bar{\beta}^{\mathrm{SHG}, \mathrm{d}}$ & $\bar{\gamma}$ & $\overline{\bar{\gamma}^{\mathrm{THG}, \mathrm{e}}}$ \\
\hline $1^{a}$ & 1.19 & 289 & 33 & 1.28 & 260 & 60 & 130 & -62.9 & -72.1 \\
\hline $1^{b}$ & 1.10 & 310 & 170 & 1.64 & 276 & 8 & 25 & -71.6 & -82.2 \\
\hline $1^{c}$ & 0.86 & 306 & 138 & 1.26 & 275 & 15 & 27 & -71.5 & -82.4 \\
\hline $2^{\mathrm{b}}$ & 1.70 & 323 & 1147 & 1.22 & 283 & 301 & 613 & -76.2 & -87.9 \\
\hline $3^{b}$ & 6.53 & 336 & 2774 & 9.80 & 318 & 2341 & 10431 & -95.9 & -100.9 \\
\hline $4^{b}$ & 7.57 & 350 & 3197 & 9.63 & 327 & 2446 & 13025 & -101.6 & -103.5 \\
\hline $5^{\mathrm{b}}$ & 5.97 & 342 & 2645 & 8.75 & 320 & 2412 & 10464 & -97.6 & -103.1 \\
\hline $6^{\mathrm{b}}$ & 2.93 & 334 & 1066 & 5.98 & 295 & 613 & 1413 & -83.0 & -95.6 \\
\hline $7^{\mathrm{b}}$ & 6.43 & 348 & 2556 & 10.17 & 323 & 2388 & 9993 & -99.2 & -105.9 \\
\hline $8^{b}$ & 5.75 & 338 & 1331 & 9.11 & 300 & 629 & 1388 & -85.8 & -99.1 \\
\hline $9^{b}$ & 5.02 & 333 & 1187 & 7.87 & 299 & 588 & 1367 & -85.3 & -98.7 \\
\hline $10^{b}$ & 6.03 & 336 & 1544 & 4.50 & 282 & 308 & 724 & -75.4 & -86.8 \\
\hline
\end{tabular}

$\mu$ in [D], $\alpha$ and $\beta$ in [a.u.], and $\gamma$ in $10^{3}$ [a.u.].

${ }^{a} X$-ray [24] structure and NLO computed at the B3LYP/6-311G level.

${ }^{b}$ B3LYP/6-311G structure and NLO computed at the B3LYP/6-311G level.

${ }^{c} B 3 L Y P / 6-31 G^{\star \star}$ structure and NLO computed at the B3LYP/6-31G ${ }^{\star \star}$ level.

${ }^{\mathrm{d}} \beta^{\text {SHG }}$ computed at $\lambda=1064.8 \mathrm{~nm}$.

e $\gamma^{\text {THG }}$ computed at $\lambda=1907.0 \mathrm{~nm}$.

170 a.u., of the unsubstituted (M)-tetrathia-[7]-helicene (1), to 1331 a.u., in the case of compound (8), where the acceptor group is $\mathrm{CHO}$ and the donor $\mathrm{OH}$, and it has its maximum value, 3197 a.u., in the case of compound (4).

The relative strength of the donors can be evaluated by comparison of $\bar{\beta}$ obtained for compounds having the same acceptor (i.e., $\mathrm{NO}_{2}$ ) but different donors. Therefore, if we compare the $\bar{\beta}$ values computed (ab initio) for molecules (3), (4), (5), and (7) we can estimated that relative strength of the acceptors is $\mathrm{Cl}<\mathrm{H}<\mathrm{OH}<\mathrm{NH}_{2}$.

In the same way, comparing the $\bar{\beta}$ computed ( $a b$ initio) for (1), (3), (6), and (9), for which the common donor is $\mathrm{H}$, the relative strength of the acceptors turns out to be $\mathrm{H}<\mathrm{CO}_{2}<\mathrm{CHO}<\mathrm{NO}_{2}$.

Indeed, the maximal values of $\bar{\beta}$ computed for molecule (4) were somehow expected because $\mathrm{NO}_{2}$ and $\mathrm{NH}_{2}$ are known to be the strongest acceptor and donor substituents within our test set.

\section{Conclusion}

We presented results obtained from both semiempirical and $a b$ initio calculations of the polarizability and hyperpolarizabilities for some substituted $(M)$-tetrathia-[7]-helicenes. We have shown that the best nonlinear optical properties were ob- tained with the nitro $\mathrm{NO}_{2}$ and the amino $\mathrm{NH}_{2}$ pair substituents. These findings are in good agreement with the qualitative rules of organic chemistry. Indeed, $\mathrm{NO}_{2}$ and $\mathrm{NH}_{2}$ groups are known to be the best electron-withdrawing and -donating group, respectively, in our series.

Calculations such as the ones presented in this article, due to their relatively low computational effort, can be fruitfully applied to perform a first screening of optical properties of new functionalized molecules to guide and help the synthesis of new efficient NLO materials. Their main aim is not to give the exact value of the static and dynamic nonlinear optical properties but to give an idea of the effect of different substituents and find trends and general rules to create new types of NLO materials. The semiempirical method used in this article can be used to explore NLO properties of large molecules with several hundreds of atoms [11].

Finally, it should be mentioned that an investigation of the UV-VIS spectra of the compounds also has been performed [27], thus giving supplementary but necessary information on the transparency to visible light of the new materials.

\section{ACKNOWLEDGMENTS}

This work is supported by the Swiss National Science Foundation and the European COST Action 
D14. The authors acknowledge Prof. C. Adamo, Ecole National de Chimie de Paris, for carrying out the semiempirical calculations.

\section{References}

1. Abe, J.; Shirai, Y. J Am Chem Soc 1996, 118, 4705.

2. Chemla, D. S.; Zyss, J. Nonlinear Optical Properties of Organic Molecules and Crystals; Academic Press: Boston, 1987.

3. Zyss, J. Molecular Nonlinear Optics; Academic Press: Boston, 1994.

4. Messier, J.; Kajzar, F.; Prasad, F. Organic Molecules for Nonlinear Optics and Photonics, NATO ASI Series; Kluwer Academic Publishers: Dordrecht, The Netherlands, 1991.

5. Zerbi, G. Organic Materials for Photonics; North-Holland: Amsterdam, 1993.

6. Groen, M. B.; Wynberg, H. J Am Chem Soc 1971, 93, 2968.

7. Yamada, K.; Tanaka, H.; Nakagawa, H.; Ogashiwa, S.; Kawazura, H. Bull Chem Soc Jpn 1982, 55, 500.

8. Groen, M. B.; Schadenberg, H.; Wynberg, H. J Org Chem 1971, 36, 2797.

9. Abe, J.; Shirai, Y.; Nemoto, N.; Miyata, F.; Nagase, Y. J Phys Chem B 1997, 101, 576.

10. Abe, J.; Shirai, Y.; Nemoto, N.; Nagase, Y. J Phys Chem B 1997, 101, 1910.

11. Karki, L.; Vance, F. W.; Hupp, J. T.; LeCours, S. M.; Therien, M. J. J Am Chem Soc 1998, 120, 2606.

12. Priyadarshy, S.; Therien, M. J.; Beratan, D. N. J Am Chem Soc 1996, 118, 1504.

13. Buckingham, A. D. Adv Chem Phys 1967, 12, 107.

14. Willetts, A.; Rice, J. E.; Burland, D. M.; Shelton, D. P. J Chem Phys 1992, 97, 7590.

15. Frisch, M. J.; Trucks, G. W.; Schlegel, H. B.; Scuseria, G. E.;
Robb, M. A.; Cheeseman, J. R.; Zakrzewski, V. G.; Montgomery, J. A. Jr.; Stratmann, R. E.; Burant, J. C.; Dapprich, S.; Millam, J. M.; Daniels, A. D.; Kudin, K. N.; Strain, M. C.; Farkas, O.; Tomasi, J.; Barone, V.; Cossi, M.; Cammi, R.; Mennucci, B.; Pomelli, C.; Adamo, C.; Clifford, S.; Ochterski, J.; Petersson, G. A.; Ayala, P. Y.; Cui, Q.; Morokuma, K.; Malick, D. K.; Rabuck, A. D.; Raghavachari, K.; Foresman, J. B.; Cioslowski, J.; Ortiz, J. V.; Baboul, A. G.; Stefanov, B. B.; Liu, G.; Liashenko, A.; Piskorz, P.; Komaromi, I.; Gomperts, R.; Martin, R. L.; Fox, D. J.; Keith, T.; Al-Laham, M. A.; Peng, C. Y.; Nanayakkara, A.; Gonzalez, C.; Challacombe, M.; Gill, P. M. W.; Johnson, B. G.; Chen, W.; Wong, M. W.; Andres, J. L.; Head-Gordon, M.; Replogle, E. S.; Pople, J. A. Gaussian 98, Revision A.7; Gaussian, Inc.: Pittsburgh, PA, 1998.

16. Becke, A. D. J Chem Phys 1993, 98, 5648.

17. (a) Hariharan, P. C.; Pople, J. A. Theor Chim Acta 1973, 28, 213; (b) Francl, M. M.; Petro, W. J.; Hehre, W. J.; Binkley, J. S.; Gordon, M. S.; DeFrees, D. J.; Pople, J. A. J Chem Phys 1982, 77,3654 .

18. (a) Krishnan, R.; Binkley, J. S.; Seeger, R.; Pople, J. A. J Chem Phys 1980, 72, 650; (b) McLean, A. D.; Chandler, G. S. J Chem Phys 1980, 72, 5639.

19. Cowell, S. M.; Murray, C. W.; Handy, N. C.; Amos, R. D. Chem Phys Lett 1993, 210, 261.

20. Lee, A. M.; Colwell, S. M. J Chem Phys 1994, 101, 9704.

21. Hurst, J.; Dupuis, M.; Clementi, E. J Chem Phys 1998, 89, 385.

22. MOS-F V3L1; Fujitsu, Ltd.: Tokyo, 1995.

23. Del Bene, J.; Jaffe, H. H. J Chem Phys 1977, 65, 2664.

24. Kurtz, A. H.; Steward, J. J. P.; Dieter, K. D. J. Comput Chem 1990, 11, 82.

25. Dewar, M.; Thiel, W. J Am Chem Soc 1977, 99, 4499.

26. Nakagawa, H.; Obata, A.; Yamada, K.; Kawazura, H.; Konno, M.; Miyamae, H. J Chem Soc Perkin Trans II 1985, 1899.

27. Daul, C.; Weber, V. (unpublished data). 